\title{
Circulating big endothelin-1: An active role in pulmonary thromboendarterectomy?
}

\author{
Frank Langer, MD, ${ }^{a}$ Michael Bauer, MD, ${ }^{b}$ Dietmar Tscholl, MD, ${ }^{a}$ Rene Schramm, MD, ${ }^{a}$ Takashi Kunihara, MD, \\ Henning Lausberg, MD, ${ }^{a}$ Thomas Georg, $\mathrm{MD}^{\mathrm{c}}$ Heinrike Wilkens, MD, ${ }^{\mathrm{d}}$ and Hans-Joachim Schäfers, MD ${ }^{\mathrm{a}}$
}

From the Department of Thoracic and Cardiovascular Surgery, University Hospital Homburg, Homburg, Germany, ${ }^{a}$ Department of Anesthesiology and Critical Care, Friedrich-Schiller-University, Jena, Germany, ${ }^{\mathrm{b}}$ Department of Epidemiology and Biostatistics, University Hospital Homburg, Homburg, Germany, ${ }^{\mathrm{c}}$ and Department of Pulmonary Medicine, University Hospital Homburg, Homburg, Germany. ${ }^{\mathrm{d}}$

Received for publication Feb 18, 2005; revisions received April 15, 2005; accepted for publication June 8, 2005.

Address for reprints: Hans-Joachim Schäfers, MD, Department of Thoracic and Cardiovascular Surgery, University Hospital Homburg, University of Saarland, Kirrberger Str, D-66421 Homburg/Saar, Germany (E-mail: chhjsc@uniklinik-saarland.de).

J Thorac Cardiovasc Surg 2005;130:1342-7

$0022-5223 / \$ 30.00$

Copyright $(\odot 2005$ by The American Association for Thoracic Surgery

doi:10.1016/j.jtcvs.2005.06.044
Background: Pulmonary thromboendarterectomy is an effective treatment for patients with chronic thromboembolic pulmonary hypertension. The early postoperative course may be associated with pulmonary vasoconstriction and profound systemic vasodilation. We investigated the potential involvement of endothelins in these hemodynamic alterations.

Methods: Seventeen patients with chronic thromboembolic pulmonary hypertension (pulmonary vascular resistance, $1015 \pm 402 \mathrm{dyne} \cdot \mathrm{s} \cdot \mathrm{cm}^{-5}$ [mean $\left.\pm \mathrm{SD}\right]$ ) underwent pulmonary thromboendarterectomy with cardiopulmonary bypass and deep hypothermic circulatory arrest. Peripheral arterial blood samples were drawn before sternotomy, during cardiopulmonary bypass before and after deep hypothermic circulatory arrest, and $0,8,16$, and 24 hours after surgery and were analyzed for big endothelin-1. The patients were divided into 2 groups according to whether their preoperative big endothelin-1 plasma level was above or below the cutoff point of 2.1 $\mathrm{pg} / \mathrm{mL}$, as determined by receiver operating characteristic curve analysis (group A, big endothelin- $1<2.1 \mathrm{pg} / \mathrm{mL}, \mathrm{n}=8$; group $\mathrm{B}$, big endothelin-1 $\geq 2.1 \mathrm{pg} / \mathrm{mL}, \mathrm{n}=9$ ).

Results: Patients in group B, with higher preoperative big endothelin-1 levels (3.2 $\pm 1.0 \mathrm{pg} / \mathrm{mL}$ vs $1.5 \pm 0.4 \mathrm{pg} / \mathrm{mL} ; P<.001$ ), were poorer operative candidates (preoperative mean pulmonary artery pressure, $51.3 \pm 7.1 \mathrm{~mm} \mathrm{Hg}$ vs $43.6 \pm 6.2$ $\mathrm{mm} \mathrm{Hg} ; P=.006$ ) and had a poorer outcome (mean pulmonary artery pressure 24 hours after surgery, $32.6 \pm 9.5 \mathrm{~mm} \mathrm{Hg}$ vs $21.8 \pm 6.2 \mathrm{~mm} \mathrm{Hg} ; P<.001)$. Positive correlations were found between preoperative big endothelin-1 levels and preoperative mean pulmonary artery pressure $(r=0.56 ; P=.02)$ as well as postoperative mean pulmonary artery pressure at 0 hours $(r=0.70 ; P=.002)$ and 24 hours $(r=$ $0.63 ; P=.006)$ after surgery. Preoperative big endothelin-1 levels predicted outcome (postoperative mean pulmonary artery pressure at 24 hours after surgery) after pulmonary thromboendarterectomy (area under the receiver operating characteristic curve, 0.85). Peak big endothelin-1 levels also correlated with maximal vasopressor dosage $(r=0.65 ; P=.004)$.

Conclusions: Preoperative big endothelin-1 levels seem to correlate with the hemodynamic alterations observed in pulmonary thromboendarterectomy and may be used to predict hemodynamic outcome after pulmonary thromboendarterectomy.

$\mathrm{P}$ ulmonary thromboendarterectomy (PTE) has been shown to be the most effective therapeutic option in severe chronic thromboembolic pulmonary hypertension $(\mathrm{CTEPH})$, with a drastic improvement in pulmonary hemodynamics and symptoms of heart failure. ${ }^{1-3}$ This procedure, however, is associated with a mortality rate of $4 \%$ to $23 \% .^{1,4-9}$ In our experience with more than 180 cases, we have seen marked hemodynamic instability during the initial phase. In approximately $25 \%$ of patients, we observed a reversible component of pulmonary vasoconstriction; in addition, there is profound systemic vasodilation that necessitates 


\author{
Abbreviations and Acronyms \\ AUC = area under the curve \\ $\mathrm{CPB}=$ cardiopulmonary bypass \\ $\mathrm{CTEPH}=$ chronic thromboembolic pulmonary \\ hypertension \\ DHCA = deep hypothermic circulatory arrest \\ ET = endothelin \\ MPAP = mean pulmonary artery pressure \\ PTE = pulmonary thromboendarterectomy \\ PVR = pulmonary vascular resistance \\ $\mathrm{ROC}=$ receiver operating characteristic
}

intensive vasopressor support. ${ }^{10}$ Postoperative pulmonary hypertension plays an important role in the occurrence of serious complications such as reperfusion edema and hemoptysis. ${ }^{4-6,10}$ The underlying pathophysiological mechanisms of this hemodynamic instability are poorly understood, but endogenous substances released in response to heart failure, surgical trauma, cardiopulmonary bypass (CPB), and deep hypothermic circulatory arrest (DHCA) may mediate the transient disturbance of vascular tone.

Regulation of endothelin (ET) expression is at the level of transcription, with stimuli including hypoxia, ischemia, shear stress, and inflammatory mediators, ${ }^{11,12}$ and increased expression has been shown to be part of the physiologic response to CPB. ${ }^{13}$ Circulating levels of ET-1 are increased in various forms of pulmonary hypertension. ${ }^{14-16}$ When we observed altered ET mediator and receptor expression in CTEPH, ${ }^{17}$ we hypothesized that ETs as important vasoactive mediators may be involved in the postoperative hemodynamic instability after PTE. The aim of this investigation was to characterize ET expression in response to PTE.

\section{Methods \\ Patients}

Seventeen consecutive patients underwent PTE for CTEPH (age, $55.9 \pm 8.9$ years; 8 men; mean pulmonary artery pressure
[MPAP], $47.7 \pm 7.6 \mathrm{~mm} \mathrm{Hg}$; pulmonary vascular resistance [PVR], $1015.4 \pm 401.8 \mathrm{dyne} \cdot \mathrm{s} \cdot \mathrm{cm}^{-5}$; New York Heart Association [NYHA] class $3.3 \pm 0.5$ [mean \pm SD]; Table 1). Seven patients (age, $61.3 \pm 12.7$ years; 2 men; normal MPAP; NYHA, $1.5 \pm 1.3$ ) undergoing elective aortic arch replacement (partial arch, $\mathrm{n}=2$; total arch, $\mathrm{n}=5$ ) under DHCA served as a control group. The study was approved by the University Hospital Ethics Review Committee, and informed consent was obtained from all patients.

\section{Surgical Procedure}

After median sternotomy, the patients were placed on CPB by bicaval and aortic cannulation and cooled to a nasopharyngeal temperature of $18^{\circ} \mathrm{C}$. Cardiac arrest was induced by infusion of blood cardioplegia into the aortic root after aortic crossclamping. The central pulmonary arteries were opened within the pericardium, and a dissection plane was developed and followed to segmental levels. ${ }^{7}$ Repeated periods of DHCA limited to 20 minutes were used to achieve accurate visualization during peripheral dissection. After completion of PTE, CPB was resumed, and the patient was rewarmed. Weaning from CPB was started after rewarming to a rectal temperature of $34^{\circ} \mathrm{C}$. Before pump flow was reduced, the mean arterial blood pressure was regulated to approximately $60 \mathrm{~mm} \mathrm{Hg}$ by using an intravenous infusion of norepinephrine if vascular resistance was low. ${ }^{10}$ Weaning from CPB was accomplished by stepwise reduction of pump flow while monitoring pulmonary artery pressures and administering volume carefully to maintain a cardiac index of more than $2.2 \mathrm{~L} \cdot \mathrm{min}^{-1} \cdot \mathrm{m}^{-2}$. If MPAP exceeded $30 \mathrm{~mm} \mathrm{Hg}$, nitroglycerin was used as an intravenous infusion to reduce preload.

For aortic arch replacement, the patients were also cooled to a nasopharyngeal temperature of $18^{\circ} \mathrm{C}$. Aortic replacement was performed in standard fashion. Hemodynamic management during weaning from $\mathrm{CPB}$ was identical to that in the PTE patients $(\mathrm{CPB}$, $114 \pm 30$ minutes; myocardial ischemia, $56 \pm 30$ minutes; DHCA, $21 \pm 8$ minutes).

\section{ET Analysis}

Arterial blood samples were drawn from the radial artery catheter before surgery (after induction of anesthesia and line placement but before sternotomy), during $\mathrm{CPB}$ before (cooling period; ap-

TABLE 1. Preoperative and intraoperative data

\begin{tabular}{|c|c|c|c|}
\hline Variable & $\begin{array}{c}\text { Group A } \\
\text { (preoperative big ET-1 }<2.1 \mathrm{pg} / \mathrm{mL} \text { ) }\end{array}$ & $\begin{array}{c}\text { Group B } \\
\text { (preoperative big ET-1 } \geq 2.1 \mathrm{pg} / \mathrm{mL} \text { ) }\end{array}$ & $P$ value \\
\hline Age (y) & $58.8 \pm 6.4$ & $53.4 \pm 10.4$ & .23 \\
\hline $\operatorname{Sex}(M / F)$ & $5 / 3$ & $3 / 6$ & 1.0 \\
\hline NYHA & $3.3 \pm 0.5$ & $3.3 \pm 0.5$ & .81 \\
\hline Angiographically involved pulmonary segments (n) & $9.2 \pm 2.4$ & $9.3 \pm 2.1$ & .86 \\
\hline CPB (min) & $126 \pm 27$ & $145 \pm 19$ & .1 \\
\hline Myocardial ischemia (min) & $72 \pm 18$ & $83 \pm 12$ & .17 \\
\hline DHCA (min) & $35 \pm 10$ & $41 \pm 9$ & .3 \\
\hline Disease type $(\mathrm{I} / \mathrm{II} / \mathrm{III} / \mathrm{IV})^{*}$ & $1 / 5 / 2 / 0$ & $1 / 3 / 5 / 0$ & \\
\hline Reopened segments (n) & $9.8 \pm 3.1$ & $8.4 \pm 3.3$ & .42 \\
\hline
\end{tabular}

Data are expressed as mean \pm SD. ET, Endothelin; NYHA, New York Heart Association; CPB, cardiopulmonary bypass; DHCA, deep hypothermic circulatory arrest. *Disease type classification is according to Thistlethwaite and associates. ${ }^{8}$ 


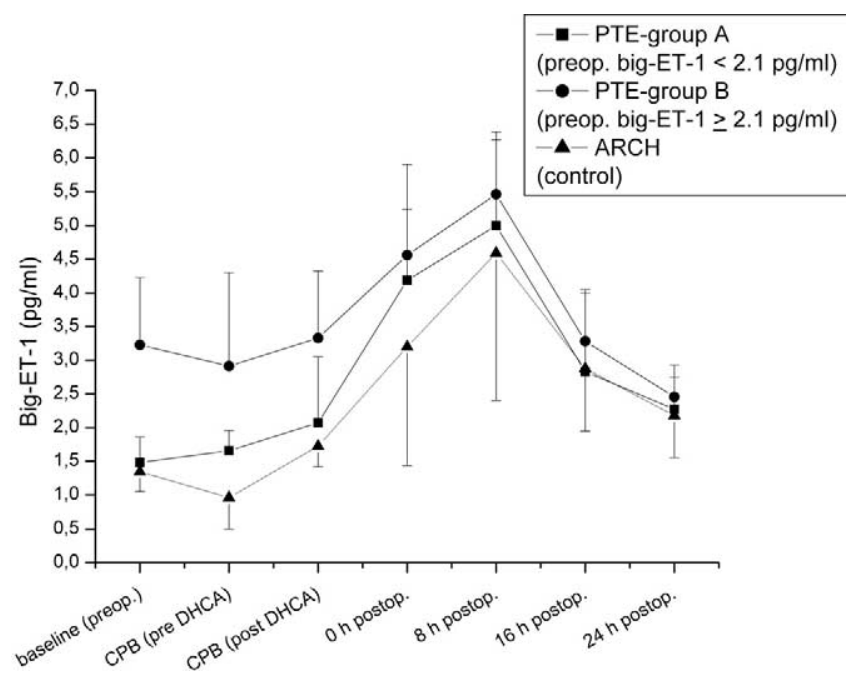

Figure 1. Big ET-1 levels during the perioperative course. Preop, Preoperative; postop, postoperative; $A R C H$, aortic arch replacement.

proximately $28^{\circ} \mathrm{C}$ nasopharyngeal temperature) and after (rewarming period; approximately $28^{\circ} \mathrm{C}$ nasopharyngeal temperature) DHCA, and 0, 8, 16, and 24 hours after arrival in the intensive care unit. Blood samples were centrifuged at $1200 \mathrm{rpm}$ for 10 minutes, and the plasmatic supernatants were analyzed for the ET prohormone big ET-1 by using a commercially available immunoassay (Biomedica, Eching, Germany) with polyclonal capture and monoclonal detection antibodies highly specific for human big ET-1 (detection limit, $0.1 \mathrm{pg} / \mathrm{mL}$ ).

\section{Statistics}

Data are shown as mean $\pm \mathrm{SD}$. Nonparametric correlation (Spearman) was applied to correlate big ET-1 levels with hemodynamic parameters and vasopressor support. The PTE patients had increased preoperative big ET-1 levels (mean, $2.4 \pm 1.2 \mathrm{pg} / \mathrm{mL}$ ). Preoperative big ET-1 levels in the control group patients were lower $(1.3 \pm 1.2 \mathrm{pg} / \mathrm{mL} ; P=.03)$. To further investigate the correlation between preoperative big ET-1 levels and postoperative MPAP, a receiver operating characteristic (ROC) curve analysis ${ }^{18}$ was performed. A cutoff point of $2.1 \mathrm{pg} / \mathrm{mL}$ (sensitivity, $100 \%$; specificity, $66.7 \%$; Figure 1) was determined for the pre- diction of increased postoperative MPAP (defined by postoperative MPAP $>30 \mathrm{~mm} \mathrm{Hg} 24$ hours after surgery) by increased preoperative big ET-1 levels. The patients were then divided into 2 groups according to whether the preoperative ET-1 level was below or above this cutoff point (group A, big ET-1 $<2.1 \mathrm{pg} / \mathrm{mL}$, $\mathrm{n}=8$; group $\mathrm{B}$, big ET-1 $\geq 2.1 \mathrm{pg} / \mathrm{mL}, \mathrm{n}=9$ ). Statistical differences between groups were assessed with a $t$ test, $\chi^{2}$ test, or 2-way repeated-measures analysis of variance (MPAP and PVR) by using standard software (SigmaStat 2.0; Jandel Scientific, San Rafael, Calif). If the analysis of variance yielded a significant $\mathrm{F}$ value $(P<.05)$, then the Bonferroni multiple $t$ test was applied for post hoc testing.

\section{Results}

In both PTE groups, big ET-1 reached comparable peak levels in response to the operative procedure (group A, $4.9 \pm$ $1.2 \mathrm{ng} / \mathrm{mL}$; group $\mathrm{B}, 5.4 \pm 1.3 \mathrm{ng} / \mathrm{mL}$ ) and declined to similar levels within 24 hours after surgery. Patients in the control group had similar levels during the postoperative course (Figure 1).

Preoperative MPAP $(51.3 \pm 7.1 \mathrm{~mm} \mathrm{Hg}$ vs $43.6 \pm 6.2$ $\mathrm{mm} \mathrm{Hg} ; P=.006)$ and PVR (1180 \pm 383 dyne $\cdot \mathrm{s} \cdot \mathrm{cm}^{-5}$ vs $829 \pm 356$ dyne $\left.\cdot \mathrm{s} \cdot \mathrm{cm}^{-5} ; P<.001\right)$ were higher in group B (Table 2), even though there were no differences in demographic data. Times for CPB, myocardial ischemia, and DHCA were similar in both PTE groups (Table 1). MPAP $(P<.001)$ and PVR $(P<.001)$ were normalized after surgery in group A. Patients in group B showed a marked decrease in MPAP $(P<.001)$ and PVR $(P<.001)$ compared with the preoperative values but had residual pulmonary hypertension (Table 2). Two patients in group B died in the early postoperative course as a result of multiple organ failure $(\mathrm{n}=1)$ and massive reperfusion edema $(\mathrm{n}=$ 1); their big ET-1 reached high peak levels of 6.1 and 6.2 $\mathrm{pg} / \mathrm{mL}$. The patient with reperfusion edema died at his individual peak big ET-1-level. All other patients were discharged from the hospital.

Preoperative big ET-1 levels correlated with preoperative MPAP $(r=0.56 ; P=.02$; Figure $2, A)$ and preoperative PVR $(r=0.52 ; P=.03)$, as well as postoperative MPAP immediately after surgery $(r=0.70 ; P=.002$; Figure $2, B)$

TABLE 2. Hemodynamic data of the 2 patient groups

\begin{tabular}{|c|c|c|c|}
\hline Variable & $\begin{array}{c}\text { Group A } \\
\text { (preoperative big ET-1 }<2.1 \mathrm{pg} / \mathrm{mL} \text { ) } \\
\end{array}$ & $\begin{array}{c}\text { Group B } \\
\text { (preoperative big ET-1 } \geq 2.1 \mathrm{pg} / \mathrm{mL} \text { ) }\end{array}$ & $P$ value \\
\hline Preoperative MPAP (mm Hg) & $43.6 \pm 6.2$ & $51.3 \pm 7.1^{*}$ & .006 \\
\hline Preoperative PVR (dyne $\cdot \mathrm{s} \cdot \mathrm{cm}^{-5}$ ) & $829 \pm 356$ & $1180 \pm 383^{*}$ & $<.001$ \\
\hline 0-h postoperative MPAP (mm Hg) & $24.3 \pm 5.9$ & $36.6 \pm 9.9^{*}$ & $<.001$ \\
\hline 0-h postoperative PVR (dyne $\cdot \mathrm{s} \cdot \mathrm{cm}^{-5}$ ) & $390 \pm 148$ & $596 \pm 190^{*}$ & .009 \\
\hline 24-h postoperative MPAP (mm Hg) & $21.8 \pm 6.2$ & $32.6 \pm 9.5^{*}$ & $<.001$ \\
\hline 24-h postoperative PVR (dyne $\cdot \mathrm{s} \cdot \mathrm{cm}^{-5}$ ) & $254 \pm 74$ & $443 \pm 198^{*}$ & .008 \\
\hline
\end{tabular}

Data are expressed as mean $\pm \mathrm{SD}$. $E T$, Endothelin; MPAP, mean pulmonary arterial pressure; $P V R$, pulmonary vascular resistance. $* P<.05$ by 2 -way repeated-measures analysis of variance and Bonferroni multiple $t$ test post hoc testing. 


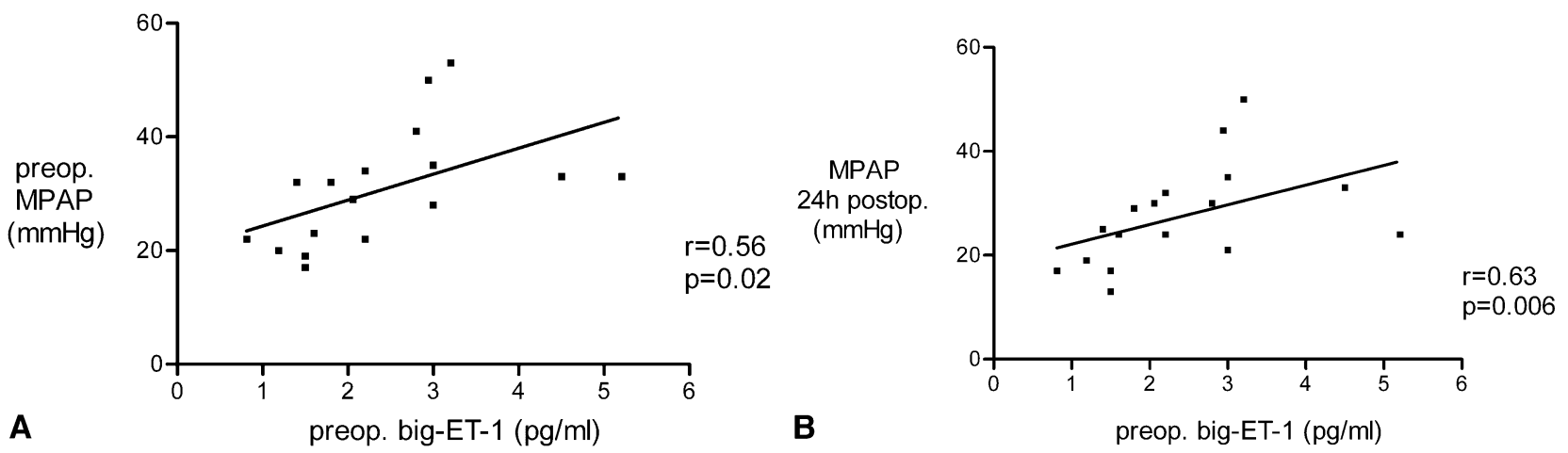

Figure 2. A, Correlation between preoperative (preop) big ET-1 and preoperative MPAP. B, Correlation between preoperative big ET-1 and MPAP 24 hours after surgery (postop).

and 24 hours after surgery $(r=0.63 ; P=.006$; Figure 2 , $C)$. In addition, the ROC curve analysis demonstrated that an increase of preoperative big ET-1 was a good predictor of poor hemodynamic outcome after PTE (postoperative MPAP $>30 \mathrm{~mm} \mathrm{Hg} 24$ hours after surgery: area under the curve [AUC], 0.85; Figure 3; postoperative PVR $>500$ dyne $\cdot \mathrm{s} \cdot \mathrm{cm}^{-5}$ : AUC, 0.77).

High vasopressor support with norepinephrine was required during the early postoperative course (group A, 0.4 $\pm 0.4 \mu \mathrm{g} \cdot \mathrm{kg}^{-1} \cdot \mathrm{min}^{-1}$; group B, $0.6 \pm 0.5 \mu \mathrm{g} \cdot \mathrm{kg}^{-1}$. $\min ^{-1}$ ) in both PTE groups, whereas only moderate vasopressor support was necessary in the control group $(0.1 \pm$ $\left.0.2 \mu \mathrm{g} \cdot \mathrm{kg}^{-1} \cdot \mathrm{min}^{-1}\right)$. It is interesting to note that a positive correlation was found between peak big ET-1 levels

$\mathrm{AUC}=0.85$

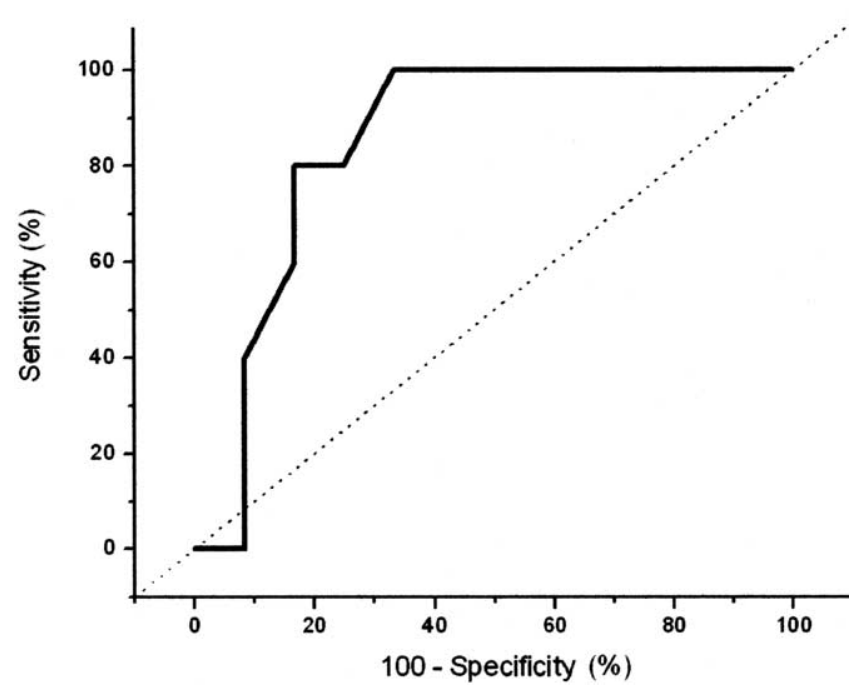

Figure 3. Receiver operating characteristic curve (AUC, area under the curve) of preoperative big ET-1 level to predict postoperative MPAP. and the maximal norepinephrine administration after surgery $(r=0.65 ; P=.004$; Figure 4$)$ in PTE patients.

\section{Discussion}

CTEPH portends a poor prognosis. ${ }^{2,19}$ Almost all patients are in NYHA stage III or IV at the time of diagnosis and operation. ${ }^{1,2}$ PTE as the most effective therapeutic approach in severe CTEPH has been demonstrated to drastically improve pulmonary hemodynamics and eliminate heart failure. ${ }^{1-3}$ This challenging surgical procedure, however, is associated with a mortality rate of $4 \%$ to $23 \% .^{1,4-9,20}$ Several investigators have previously tried to identify risk factors to predict the outcome of CTEPH patients after PTE and found that the severity of disease was associated with perioperative mortality. ${ }^{1,4-6,8}$ We have seen a reversible component of pulmonary vasoconstriction in the early postoperative course ( $<48$ hours) in a significant proportion of patients that may trigger lethal complications such as fulminant reperfusion edema and hemoptysis., ${ }^{2,41}$ In parallel, profound systemic vasodilatation is frequently observed, and this necessitates intensive vasopressor support to maintain

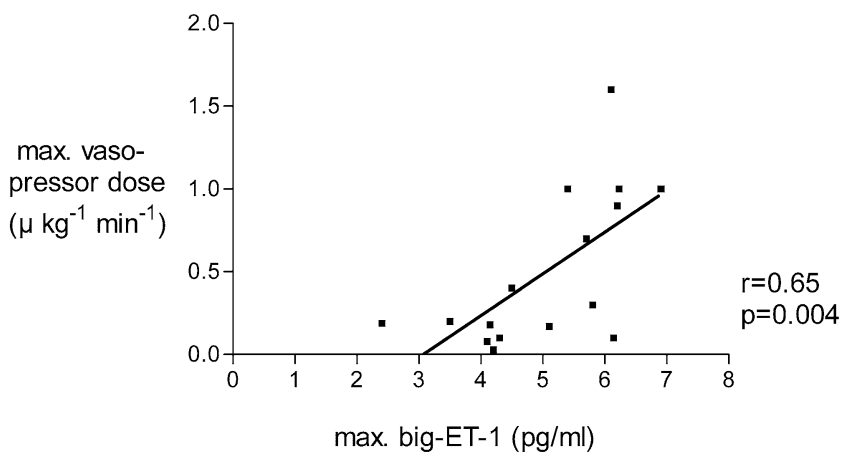

Figure 4. Correlation between peak big ET-1 and maximal vasopressor dosage. 
adequate systemic blood pressure. ${ }^{10}$ The underlying pathophysiological mechanisms of these hemodynamic alterations have not yet been elucidated.

A threefold to sixfold increase of systemic ET levels has been observed immediately after cardioplegic arrest and reperfusion in standard cardiac surgical procedures. ${ }^{13} \mathrm{Be}-$ cause PTE is a major insult to the pulmonary vascular endothelium and requires long CPB and DHCA times, ${ }^{1,7}$ an increased ET release should be expected. ET activity has also been shown to be increased in various forms of pulmonary hypertension ${ }^{14-16}$ and correlates with the severity of disease in patients with primary pulmonary hypertension. ${ }^{22}$ Because we have found increased big ET-1 levels and altered receptor expression in patients with CTEPH, ${ }^{17}$ we hypothesized that the ET system might be involved in these hemodynamic alterations in the early postoperative course after PTE. To eliminate the confounding factor of big ET-1 release in response to CPB and DHCA, we also determined big ET-1 levels in patients with aortic arch replacement.

ETs are synthesized as preprohormones and posttranslationally processed to vasoactive peptides. ${ }^{23}$ Big ET- 1 is the 39 -amino acid prohormone with approximately $1 \%$ of the vasoactive potency of ET-1. ${ }^{23}$ After cleavage by the ETconverting enzyme, ${ }^{23}$ functional ET-1 regulates vascular tone through binding to its cellular receptors. ${ }^{11,12}$ ET-A receptors are expressed primarily on vascular smooth muscle cells and mediate a profound vasoconstriction and proliferation. ${ }^{11,12}$ In the normal pulmonary vasculature, ET-B receptors are predominantly located on endothelial cells and promote vasodilation via increased nitric oxide and prostacyclin production, as well as inhibition of the ET-converting enzyme and pulmonary clearance of ET-1. ${ }^{11,12,24}$ Nitric oxide and prostacyclin also negatively feed back on the ET mediator system by inhibition of prepro-ET-1 transcription. In the pathologic setting of pulmonary hypertension, ${ }^{24}$ however, a subpopulation of ET-B receptors located on vascular smooth muscle cells may actually contribute to vasoconstriction, ${ }^{25,26}$ possibly as a result of upregulation of ET-B receptors. Kim and colleagues ${ }^{27}$ documented an increased intensity of ET-A and ET-B receptor activity in a rat model of chronic unilateral pulmonary artery ligation, and upregulation of ET-B receptor expression has been observed in the pulmonary arteries of patients with $\mathrm{CTEPH}^{17}$ and primary pulmonary hypertension. ${ }^{28}$ Thus, there is increasing evidence that the hemodynamic effects of ET-1 depend on the differential expression and localization of ET receptor subtypes, which vary among disease types. ${ }^{24}$ ET-1 may therefore result in predominant vasoconstriction or vasodilation.

Our current investigation documented a positive correlation between preoperative big ET-1 levels and the severity of disease in CTEPH, which has not been reported previously. It is interesting to note that preoperative big ET-1 levels also correlated with postoperative MPAP, even though post- operative circulating big ET-1 levels were similarly low in all patients. (The only exception was the patient who died from reperfusion edema at his individual peak big ET-1 level.) This was supported by the ROC curve analysis, which provides a method for synthesizing the sensitivity and specificity of a diagnostic test across a spectrum of possible cutoff points. The AUC can be interpreted as the probability of a correct prediction. ${ }^{18}$ Preoperative big ET-1 levels may thus serve as a predictor of outcome after PTE in selected cases when patient selection remains difficult with the standard diagnostic tools, eg, right heart catheterization, pulmonary angiography, computed tomography, and ventilation/perfusion scintigraphy. ${ }^{1,29}$

The need for vasopressor support is common in cardiac operations, especially in procedures that necessitate long CPB times and DHCA. In concordance with this general experience, our control group also required vasopressor support. However, the dose of vasopressor support required in PTE patients was increased fourfold to fivefold. The reason for this profound vasodilation or decreased response to vasopressors is still unclear. It is interesting to note that our data suggest that the ET system may be involved in the regulation of systemic vascular tone early after PTE. Peak plasma levels of big ET-1 correlated with the maximal vasopressor dosage required within the first 24 hours after surgery. This may be due to downregulation of ET-A receptors in the systemic circulation, as seen in patients with primary pulmonary hypertension as an adaptive response to increased levels of ET- $1 .{ }^{28}$

In summary, our data suggest an active role of the ET system in the pathophysiology of CTEPH. Preoperative big ET-1 levels correlate with the severity of CTEPH and may allow prediction of hemodynamic instability and poor outcome after PTE. Because we saw similar levels of the vasoactive mediator in response to the operative procedure, differences in vascular tone after PTE may involve altered receptor expression and distribution in patients with advanced CTEPH, even though our current data do not provide proof this hypothesis. Future research will have to address both pulmonary and systemic circulation to characterize a presumptive heterogeneity in receptor expression and distribution, as well as other relevant mediator systems.

We thank Filiberto Rodriguez, MD, and Katherine B. Harrington, BA (Stanford University, Stanford, Calif), for assistance with the manuscript.

\section{References}

1. Jamieson SW, Kapelanski DP, Sakakibara N, Manecke GR, Thistlethwaite PA, Kerr KM, et al. Pulmonary endarterectomy: experience and lessons learned in 1,500 cases. Ann Thorac Surg. 2003;76:1457-64.

2. Fedullo PF, Auger WR, Kerr KM, Rubin LJ. Chronic thromboembolic pulmonary hypertension. $N$ Engl J Med. 2001;345:1465-72.

3. Archibald CJ, Auger WR, Fedullo PF, Channick RN, Kerr KM, Jamieson SW, et al. Long-term outcome after pulmonary thromboendarterectomy. Am J Respir Crit Care Med. 1999;160:523-8. 
4. Daily PO, Dembitsky WP, Iversen S, Moser KM, Auger W. Risk factors for pulmonary thromboendarterectomy. J Thorac Cardiovasc Surg. 1990;99:670-8.

5. Hartz RS, Byrne JG, Levitsky S, Park J, Rich S. Predictors of mortality in pulmonary thromboendarterectomy. Ann Thorac Surg. 1996;62: 1255-9.

6. Tscholl D, Langer F, Wendler O, Wilkens H, Georg T, Schäfers HJ. Pulmonary thromboendarterectomy-risk factors for early survival and hemodynamic improvement. Eur J Cardiothorac Surg. 2001;19: 771-6.

7. Daily PO, Dembitsky WP, Jamieson SW. The evolution and the current state of the art of pulmonary thromboendarterectomy. Semin Thorac Cardiovasc Surg. 1999;11:152-63.

8. Thistlethwaite PA, Mo M, Madani MM, Deutsch R, Blanchard D, Kapelanski DP, et al. Operative classification of thromboembolic disease determines outcome after pulmonary endarterectomy. $J$ Thorac Cardiovasc Surg. 2002;124:1203-11.

9. Masuda M, Nakajima N. Our experience of surgical treatment for chronic pulmonary thromboembolism. Ann Thorac Cardiovasc Surg. 2001;7:261-5.

10. Mares P, Gilbert TB, Tschernko EM, Hiesmayr M, Muhm M, Herneth A, et al. Pulmonary artery thromboendarterectomy: a comparison of two different postoperative treatment strategies. Anesth Analg. 2000; 90:267-73

11. Fagan K, McMurtry I, Rodman D. Role of endothelin-1 in lung disease. Respir Res. 2001;2:90-101.

12. Levin ER. Endothelins. N Engl J Med. 1995;333:356-63.

13. Spinale FG. The bioactive peptide endothelin causes multiple biologic responses relevant to myocardial and vascular performance after cardiac surgery. J Thorac Cardiovasc Surg. 2002;123:1031-4.

14. Giaid A, Yanagisawa M, Langleben D, Michel RP, Levy R, Shennib $\mathrm{H}$, et al. Expression of endothelin-1 in the lungs of patients with pulmonary hypertension. N Engl J Med. 1993;328:1732-9.

15. Dupuis J, Cernacek P, Tardif JC, Stewart DJ, Gosselin G, Dyrda I, et al. Reduced pulmonary clearance of endothelin-1 in pulmonary hypertension. Am Heart J. 1998;135:614-20.

16. Stewart DJ, Levy RD, Cernacek P, Langleben D. Increased plasma endothelin-1 in pulmonary hypertension: marker or mediator of disease? Ann Intern Med. 1991;114:464-9.

17. Bauer M, Wilkens H, Langer F, Schneider SO, Lausberg H, Schäfers HJ. Selective upregulation of endothelin B receptor gene expression in severe pulmonary hypertension. Circulation. 2002;105:1034-6.
18. Grunkemeier GL, Jin R. Receiver operating characteristic curve analysis of clinical risk models. Ann Thorac Surg. 2001;72:323-6.

19. Riedel M, Stanek V, Widimsky J, Prerovsky I. Longterm follow-up of patients with pulmonary thromboembolism. Late prognosis and evolution of hemodynamic and respiratory data. Chest. 1982;81: 151-8.

20. Daily PO, Dembitsky WP, Peterson KL, Moser KM. Modifications of techniques and early results of pulmonary thromboendarterectomy for chronic pulmonary embolism. J Thorac Cardiovasc Surg. 1987;93: 221-33.

21. Tachibana K, Imanaka H, Miyano H, Takeuchi M, Kumon K, Ando M, et al. Recruitment maneuver and high PEEP in a patient with severe reperfusion pulmonary edema after pulmonary thromboendarterectomy [in Japanese]. Masui. 2003;52:52-7.

22. Rubens C, Ewert R, Halank M, Wensel R, Orzechowski HD, Schultheiss HP, et al. Big endothelin-1 and endothelin-1 plasma levels are correlated with the severity of primary pulmonary hypertension. Chest. 2001;120:1562-9.

23. Yanagisawa M, Kurihara H, Kimura S, Tomobe Y, Kobayashi M, Mitsui Y, et al. A novel potent vasoconstrictor peptide produced by vascular endothelial cells. Nature. 1988;332:411-5.

24. Channick RN, Sitbon O, Barst RJ, Manes A, Rubin LJ. Endothelin receptor antagonists in pulmonary arterial hypertension. J Am Coll Cardiol. 2004;43(12 suppl S):62S-67S.

25. Masaki T. Possible role of endothelin in endothelial regulation of vascular tone. Annu Rev Pharmacol Toxicol. 1995;35:235-55.

26. Dupuis J, Jasmin JF, Prie S, Cernacek P. Importance of local production of endothelin-1 and of the ET(B) receptor in the regulation of pulmonary vascular tone. Pulm Pharmacol Ther. 2000; 13:135-40.

27. Kim H, Yung GL, Marsh JJ, Konopka RG, Pedersen CA, Chiles PG, et al. Pulmonary vascular remodeling distal to pulmonary artery ligation is accompanied by upregulation of endothelin receptors and nitric oxide synthase. Exp Lung Res. 2000;26:287-301.

28. Kuc RE, Davenport AP. Endothelin-A-receptors in human aorta and pulmonary arteries are downregulated in patients with cardiovascular disease: an adaptive response to increased levels of endothelin-1? J Cardiovasc Pharmacol. 2000;36(5 suppl 1):S377-9.

29. Fedullo PF, Auger WR, Channick RN, Moser KM, Jamieson SW. Chronic thromboembolic pulmonary hypertension. Clin Chest Med. 1995;16:353-74. 